\title{
REVIEW
}

\section{Combatting resistance in intensive care: the multimodal approach of the Spanish ICU "Zero Resistance" program}

\author{
José Garnacho Montero', Francisco Álvarez Lerma², Paula Ramírez Galleymore ${ }^{3}$, Mercedes Palomar Martínez ${ }^{4}$, \\ Luis Álvarez Rocha ${ }^{5}$, Fernando Barcenilla Gaite ${ }^{4}$, Joaquín Álvarez Rodríguez ${ }^{6}$, Mercedes Catalán González, \\ Inmaculada Fernández Moreno ${ }^{8}$, Jesús Rodríguez Baño ${ }^{9}$, José Campos ${ }^{10}$, Jesús Ma Aranaz Andrés ${ }^{11}$, \\ Yolanda Agra Varela ${ }^{12}$, Carolina Rodríguez Gay ${ }^{12}$, Miguel Sánchez García ${ }^{13^{*}}$ and The Scientific Expert Committee \\ for the "Zero Resistance" Project
}

\begin{abstract}
This article is one of ten reviews selected from the Annual Update in Intensive Care and Emergency Medicine 2015 and co-published as a series in Critical Care. Other articles in the series can be found online at http://ccforum.com/series/annualupdate2015. Further information about the Annual Update in Intensive Care and Emergency Medicine is available from http://www. springer.com/series/8901.
\end{abstract}

\section{Introduction}

Over the last few decades, a dramatic worldwide increase in infection rates by multidrug-resistant (MDR) pathogens has occurred, which is acknowledged as a public health crisis [1]. Management of infections caused by these pathogens is often difficult due to the scarcity of available active drugs.

The last report of the European Antimicrobial Resistance Surveillance System (EARSS) network, which includes 30 European countries, describes a general European-wide increase in antimicrobial resistance for the Gram-negative pathogens under surveillance (Escherichia coli, Klebsiella pneumoniae and Pseudomonas aeruginosa) [2]. High proportions of antimicrobial-resistant $P$. aeruginosa have been reported by many European countries [3]. In a study performed in 2000 in Spain, 41\% of Acinetobacter baumannii isolates were resistant to carbapenems [4]. Indeed, the rate of carbapenem resistance has increased

\footnotetext{
* Correspondence: miguel.sanchez@salud.madrid.org

${ }^{13}$ Hospital Clínico San Carlos, Madrid, Spain

Full list of author information is available at the end of the article
}

dramatically over the last decade, especially in the critical care setting [5]. An ominous emerging threat is the appearance of Gram-negative microorganisms harboring new beta-lactamases that confer high-level resistance to all available classes of beta-lactam antibiotics [6]. Concerning Gram-positive bacteria, methicillin-resistant Staphylococcus aureus (MRSA) and Enterococcus spp. resistant to vancomycin continue to be the most problematic pathogens. The incidence of MRSA infections seems to have remained stable over recent years, although this pathogen causes severe infections [2,7].

The issue of increasing incidence of MDR is clearly more complex in intensive care units (ICUs), where selection pressure and emergence of resistance, as well as the risk of patient-to-patient transmission, are highest. The Spanish annual April-to-June ICU National Nosocomial Infection Surveillance Study (Estudio Nacional de Vigilancia de Infección Nosocomial, [ENVIN]) confirms that multi-drug resistance is an unresolved problem in Spanish intensive care, with worrisome rates of Gramnegative MDR pathogens [7].

In addition, MDR microorganisms often do not cause true infection, but only colonization, constituting a hidden reservoir for the spread of these pathogens. Importantly, a high proportion of these patients receive antimicrobial treatment.

The prognosis of patients who develop nosocomial infection in the ICU is poor, especially if an MDR pathogen is involved [8]. Mortality rates and economic burden are significantly higher in infections caused by MDR pathogens, than in those caused by susceptible organisms [9]. Moreover, even the acquisition of an MDR pathogen, without concomitant infection, is associated 
with an increased risk of death, length of hospitalization, and cost $[10,11]$.

\section{Previous programs in Spanish ICUs}

The Spanish Society of Intensive Care Medicine and Coronary Care Units (SEMICYUC) and the Spanish Society of Intensive Care Nursing (SEEIUC) have recently completed their role as technical lead for two programs aimed at reducing ICU-acquired infections, namely catheter-related bloodstream infections ["Zero Bacteremia"] and ventilator-associated pneumonia (VAP) ["Zero VAP"]. Both projects were developed within a framework of "Zero Tolerance". "Zero Bacteremia" and "Zero VAP" were both promoted by the Spanish Ministry of Health, more than 200 ICUs participated, and the programs consisted of the implementation of evidence-based infection prevention bundles for catheter-related bloodstream infection and VAP. Highly successful results for both initiatives confirmed that these practices could be systematically implemented across Spain, could reduce the rates of these infections and could contribute to diminish antimicrobial use in the participating ICUs $[12,13]$.

\section{Methodology of "Zero Resistance"}

With the experience gained in the two previous projects, a new project named "Zero Resistance" was developed by the SEMICYUC with the support of the Spanish Ministry of Health. This project uses the same structure created for "Zero Bacteremia" and "Zero VAP", which is based on coordination at national, regional and local levels.

A Scientific Expert Committee (SEC) for the development and implementation of this program was appointed as follows: SEMICYUC nominated nine intensivists chosen for their expertise in the field of prevention and management of infections in the critical care setting and SEEIUC designated an intensive care nurse with experience in infection control. A microbiologist, an epidemiologist, an infectious diseases specialist, and two technicians from the Ministry of Health with broad knowledge in the field were also incorporated.

The members of the SEC reviewed the available evidence in PubMed indexed papers, including observational studies, clinical trials, guidelines, systematic reviews and meta-analyses. The following databases were searched: Medline, Embase, the Cochrane Library, and Centre for Reviews and Dissemination, including the National Health Service Economic Evaluation Database and the Health Technology Assessment database.

The implementation of 'bundles' of effective measures, compared to individual interventions, has been proposed to reduce the incidence of catheter-related bloodstream infections or VAP $[14,15]$. With this concept in mind, the SEC developed a bundle of 10 recommendations that was discussed and approved after review and analysis of the existing scientific literature. Admittedly, the evidence supporting some of the chosen recommendations is weak, but all were deemed to reach at least the level of 'expert recommendation'. No grading system was used to support the strength and quality of recommendations. All items include comments intended to facilitate local adaptations.

Criteria for defining MDR pathogens vary from institution to institution and are also not uniform in the published literature, although the most highly resistant strains are readily recognizable. Based on the pathogens considered most problematic in Spanish ICUs, "Zero Resistance" collects information on episodes of infection and colonization of the pathogens listed in Table 1. Finally, because acquiring an infection may be the result of errors in patient-care, all three programs were designed to reduce and prevent these by incorporating an integral patient safety program [16].

\section{Objectives}

The main objective of the "Zero Resistance" project is reduction in the cumulative incidence of patients with ICU-acquired MDR infections by $20 \%$. Secondary objectives are to study the epidemiology of MDR infections in Spanish ICUs, to be able to distinguish imported from ICU-acquired cases, to promote and strengthen safety assurance in participating units, and to create a network of ICUs implementing safe, and evidence-based practices. "Zero Resistance" has been active since April 2014.

\section{The bundle}

The primary aim of the bundle recommendations is reduction of the three most influential factors contributing to the development and transmission of MDR, namely:

\begin{tabular}{|c|c|}
\hline Microorganism & Resistance marker \\
\hline \multicolumn{2}{|l|}{ Gram-positive } \\
\hline Staphylococcus aureus & Methicillin (MRSA) \\
\hline Enterococcus spp. & Vancomycin (VRE) \\
\hline \multicolumn{2}{|l|}{ Gram-negative } \\
\hline \multirow[t]{2}{*}{ Enterobacteriaceae } & $\begin{array}{l}\text { 3rd generation cephalosporins } \\
\text { (particularly ESBL-producing) }\end{array}$ \\
\hline & $\begin{array}{l}\text { Carbapenems (particularly } \\
\text { carbapenemase-producing) }\end{array}$ \\
\hline Pseudomonas aeruginosa & $\begin{array}{l}\geq 3 \text { antibiotic classes, including } \\
\text { carbapenems }^{\mathrm{a}} \text {, cephalosporins }{ }^{\mathrm{b}}, \\
\text { piperacillin-tazobactam, flouroquinolones, } \\
\text { aminoglycosides }^{\mathrm{d}} \text { and colistin }\end{array}$ \\
\hline Acinetobacter baumannii & Carbapenems \\
\hline
\end{tabular}

amipenem, meropenem or doripenem; ${ }^{\mathrm{b}}$ ceftazidime or cefepime; ciprofloxacin or levofloxacin; gentamicin, tobramycin or amikacin. ESBL: extended spectrum beta-lactamase; MRSA: methicillin-resistant Staphylococcus aureus; VRE: vancomycin-resistant enterococcus. 
1) adequate prescription of antibiotics; 2) early detection and prevention of cross-colonization of MDR; and 3) elimination of reservoirs [8].

1. First recommendation: In each ICU, at least one intensivist will be designated as responsible for the use of antimicrobials. He/She should have extensive experience in infection control and in the treatment of severe infections. This/these physician(s) should routinely assess antimicrobial prescription and advise attending clinicians. Analysis of antimicrobial use should include:

a. Review of the indication for antimicrobials,

b. Evaluation of the appropriateness of the antimicrobial and the correct administration (dosing, intervals and duration),

c. Evaluation of de-escalation of antimicrobial therapy or even antimicrobial cessation.

Rationale: Antibiotic prescription in the critical care setting is a complex task that requires profound and extensive knowledge. Moreover, many pathophysiological changes associated with severe acute illness or sepsis, like capillary leak, third spacing, increased volume of distribution, and impaired renal and/or liver function, affect antimicrobial pharmacokinetics/ pharmacodynamics [17]. Therefore, it is imperative to identify intensivists with a profound knowledge of infectious diseases in critically ill patients in order to improve prescription quality. This implies choosing optimal empirical antibiotics, appropriate mode of administration, and correct dosage. Administration of antimicrobials to severely ill patients at dosages defined in studies conducted in healthy volunteers often achieves only suboptimal serum concentrations, which are associated with treatment failure and resistance development $[17,18]$. Prompt and adequate antimicrobial therapy reduces morbidity and mortality in severe sepsis and septic shock [19]. However, as soon as microbiological information is available, empiric therapy should be adapted, if appropriate, by either reduction in number and/or narrowing of antimicrobial spectrum. Notwithstanding, many clinicians are reluctant to stop antimicrobials if the patient is improving. In fact, de-escalation of empirical therapy is performed in less than $50 \%$ of patients [20].

Recent studies have shown that de-escalation is safe even in critically ill patients with severe sepsis [21] or immunosuppression [22].

2. Second recommendation: Empirically administer antimicrobials active against MDR pathogens only in cases of severe sepsis or septic shock and high risk of
MDR pathogen(s) based on patient risk factors and/or knowledge of local ecology. Otherwise, narrow-spectrum or withholding of antimicrobials is recommended until microbiological results become available and targeted therapy with antibiotics active against MDR pathogens (carbapenems, colistin, tigecycline, glycopeptides, daptomycin, linezolid) should be started if needed. In all cases, samples for culture of the potential sources of infection should be obtained before starting antibiotic therapy.

Rationale: Early and adequate antimicrobial therapy is associated with increased survival in patients with severe sepsis and septic shock [19]. However, delaying antimicrobial therapy until microbiological confirmation is available has been shown to be associated with similar outcomes in febrile surgical ICU patients compared to starting antimicrobials immediately after the clinical diagnosis of infection [23]. More recently, a quasi-experimental, before-after observational cohort study concluded that, after adjusting for confounders, aggressive antimicrobial therapy was an independent predictor of mortality. In the aggressive period, antimicrobial treatment was always started in patients suspected of having an infection after appropriate cultures were obtained. In the second period (conservative strategy), antimicrobial treatment was started only after objective findings confirmed the infection [24]. The main limitation of both studies is that they were carried out in surgical patients and data from medical units are lacking. However, it is important to keep in mind that in febrile patients with severe sepsis or septic shock a delay in antimicrobial therapy may be fatal. In addition, the choice of empirical antimicrobial therapy should be based on an updated knowledge of the local ecology. Therefore, it seems prudent to recommend starting empiric antimicrobials active against MDR pathogens immediately only in cases meeting criteria for severe sepsis or septic shock and risk factors for MDR pathogens. Obviously, efforts to reduce the delay of microbiological results (use of rapid diagnostic techniques, direct contact with the microbiologist ...) and close follow-up of the clinical course to rapidly detect signs of alarm are fully endorsed.

3. Third recommendation: In each Unit, at least one nurse will be designated as leader of this project and responsible for infection control measures aimed at reducing transmission of MDR pathogens.

Rationale: Success of quality control programs is particularly dependent on the involvement of all categories of healthcare professionals. Nurses play a critical role in preventing and controlling infectious 
diseases and measures to prevent patient-to-patient transmission are a significant component of care. A multidisciplinary team approach is necessary to develop and implement strategies to prevent infection in the critically ill patient. The participation of nurses is of extraordinary importance for the success of infection control programs in intensive care $[25,26]$. In fact, most procedures performed to reduce the risk of nosocomial infection (vascular catheter care, artificial airway care, mouth hygiene, etc.) are part of the nurse's daily tasks.

Programs that have achieved significant reductions in nosocomial infection rates have designated at least one physician and one nurse in each ICU as team leaders [14]. This model has also been implemented by successful programs designed to reduce nosocomial infection rates in the ICU endorsed by SEMICYUC [11]. The "Zero

Resistance" program clearly supports the nomination in every ICU of a nurse leader responsible for infection control to reduce nosocomial infections and transmission of MDR pathogens.

4. Fourth recommendation: It is recommended to perform an active search for MDR pathogens in all patients on admission to the unit and at least once a week throughout their stay. These samples will be processed to identify MDR pathogens according to the local epidemiology and in collaboration with the Microbiology Service and Infection Control Team of each hospital.

Rationale: Guidelines for MDR organisms include recommendations for routine screening cultures and contact precautions for patients after admission to high-risk units, e. g., ICUs [6,27]. The implementation of contact precautions in patients colonized or infected with MDR is widely accepted. In contrast, the use of routine surveillance cultures in MDR management is still a matter of debate and not widely performed [28]. Initial screening is specially recommended for MRSA, although the same principles and practices apply to Gram-negative MDR organisms, which actually now constitute the main threat.

Active surveillance programs are time and resource-consuming. The type and number of samples are selected according to local resources and epidemiology and should include at least nasal, rectal and oropharyngeal swabs (bronchial aspirates in intubated patients) [29]. In addition, other samples may be necessary to control potential reservoirs (infections, skin ulcers, etc.).

Concerning surveillance cultures, two approaches are acceptable: All patients are screened at ICU admission or only those patients with at least one of the risk factors included in the checklist (see Fifth Recommendation).

5. Fifth recommendation: At admission to the ICU, a 'Checklist' of risk factors (Table 2) must be completed to identify patients at high risk of MDR pathogen carriage. Patients meeting at least one of the risk factors must be cared for under application of contact precautions pending culture results. Rationale: Several risk factors associated with carriage of MDR at admission to the hospital or to the ICU have been identified: Prior antibiotic use, the presence of invasive devices and certain underlying diseases are the most frequently reported [30]. Patients at risk of nosocomial pneumonia caused by MDR pathogens according to American Thoracic Society/Infectious Diseases Society of America (ATS/IDSA) criteria are: Current hospitalization of 5 days or more, prior antibiotic therapy, prior hospitalization, residence in a nursing home or extended-care facility, home infusion therapy within 30 days, chronic dialysis within 30 days, home wound care, family member with an MDR pathogen, and immunosuppression. However, in a prospective evaluation, although these criteria had an excellent negative predictive value (96\%), they had a very low positive predictive value (18\%) for infection or colonization with an MDR pathogen at ICU admission [31]. In a case-control study, immunosuppression was not independently associated with MDR bacteria in the ICU [32].

In other studies, risk factors for specific pathogens, like MRSA or A. baumannii, have been identified in an attempt to establish control measures that limit spread [33]. This approach is particularly indicated in ICUs in which a particular microorganism causes the majority of episodes of colonization/infection.

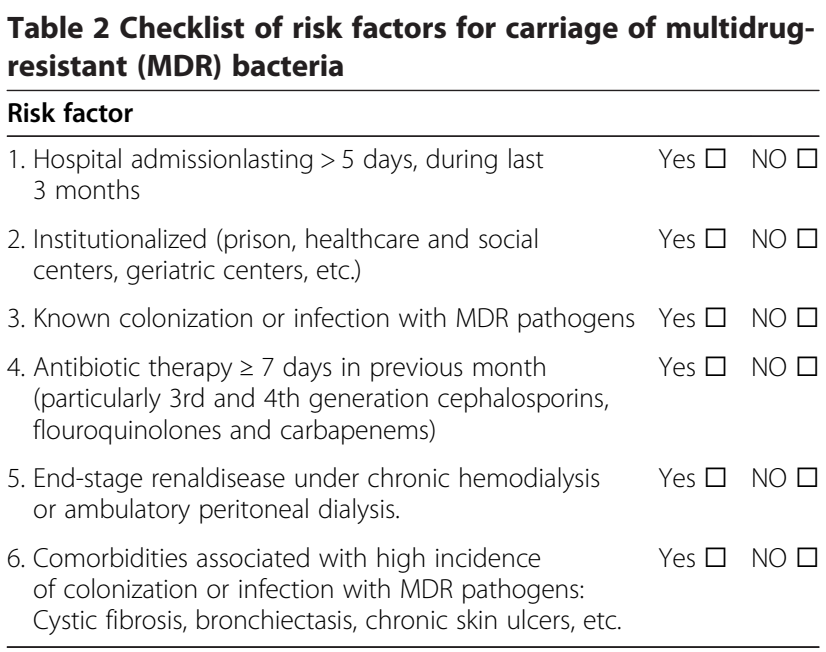


With this information, the SEC generated a Checklist (Table 2) for detection of patients at high risk of carrying MDR pathogens. If one or more of these risk factors is present, screening cultures at ICU admission is mandatory and the patient must be placed in contact isolation until culture results are negative for the target organisms. The prospective validation of this Checklist is one of the pending tasks of this program.

6. Sixth recommendation: Compliance with preventive measures including those based on transmission mechanisms should be routinely measured. Rationale: Contact precaution and hand hygiene are the mainstay for reducing transmission of microorganisms [34,35]. Adherence to these practices must be continuously reinforced and monitored [36]. Briefly, contact precautions (by staff and visitors) consist of: Hand hygiene and donning of gown and gloves immediately prior to room entry, and disposal of gown and gloves inside the patient's room, followed by hand hygiene immediately prior to leaving the room.

Adherence rates for contact precautions in ICU settings with availability of all facilities were between 75 and $80 \%$ in one study [8]. Correct practice includes: (1) Use of a contact precautions sign for every patient colonized/infected by MDR pathogens; (2) availability of contact precautions equipment at patient room entry; (3) barrier disposal containers inside patient room; and (4) monitoring of adherence to the contact precautions protocol by staff/visitors. If there are no closed rooms, precautions must be tightened.

To achieve the desired results, all staff members should watch compliance with preventive measures. Concerning this issue, the SEC of "Zero Resistance" considers that nurses have a special responsibility in implementing effective prevention. Therefore, the rest of the hospital staff and visitors must follow their recommendations.

7. Seventh recommendation: All Units should develop a cleaning protocol for rooms of patients with $M D R$ pathogens.

Rationale: Many published outbreaks of MDR pathogens detect a common source on environmental surfaces and in moist areas. Studies have documented a widespread deficiency in cleaning practices. Nevertheless, substantial improvements in cleaning and disinfection can be achieved by using standardized protocols in the ICU [37-39]. Cleaning procedures must be adapted to the architectural characteristics of each unit and agreed upon with the cleaning staff and the nosocomial infection control committee. Feedback to all involved personnel is imperative to maintain the benefits. This protocol should include fixed structures (floors and walls) as well as the bed (including main structure, rails and mattress). Cleaning protocols will include daily cleaning and final cleaning at patient discharge. Cleaning protocols for rooms occupied by patients with MDR pathogens must specify methodology, frequency of cleaning and disinfectant products. Because different cleaning products are approved in each hospital, the exact composition or trademark should be specified in the protocol. If deemed necessary, controls will be established to ensure MDR eradication [39].

8. Eighth recommendation: A file/document specifying the existing equipment in the ICU and its respective cleaning protocols should be available and updated. Rationale: Any clinical or technological equipment could act as a microbiological reservoir for MDR pathogens. Therefore, the first action is to remove all expendable materials, leaving work surfaces as free as possible. Equipment should be filed and information on the following aspects provided: Staff responsible for cleaning, cleaning schedule and cleaning methodology (disinfection, sterilization). Each healthcare worker is responsible for cleaning and disinfection of equipment for personal use (stethoscopes, flashlights ...) [40].

9. Ninth recommendation: To include products containing 4\% chlorhexidine in daily patient hygiene if colonized or infected with MDR pathogens. Rationale: Several observational studies and singlecenter trials have concluded that daily chlorhexidine bathing of ICU patients reduces the acquisition of MDR pathogens and the incidence of certain infections [40-43]. A systematic review concluded that chlorhexidine body-washing may be effective in preventing carriage, and possibly bloodstream infections, with Gram-positive MDR pathogens (MRSA and vancomycin-resistant enterococci [VRE]), whereas the evidence that this intervention eradicates carriage or prevents infection with Gram-negative MDR pathogens is weak [44]. In a recent randomized multicenter trial carried out in 13 ICUs, the effect of different infection control strategies on acquisition of MDR pathogens was assessed. Improved hand hygiene plus unit-wide chlorhexidine body-washing reduced acquisition, particularly of MRSA [45]. Interestingly, in the context of sustained high level compliance of hand hygiene and chlorhexidine bathing, screening and isolation of carriers did not reduce acquisition rates of MDR pathogens. More recently, a multicenter, open, crossover trial documented the clinical benefits of daily bathing with chlorhexidine-impregnated 
washcloths in reducing the risks of acquisition of MDR and the development of hospital-acquired bacteremia [46].

Chlorhexidine solutions must contain 0.16 grams of chlorhexidine (digluconate) per liter (dissolve $20 \mathrm{ml}$ of $4 \%$ chlorhexidine in 1 liter of warm water).

Contraindications for chlorhexidine use and adverse reactions should be taken into account. Because chlorhexidine is a cationic molecule, its activity can be reduced by natural soaps, various inorganic anions, non-ionic surfactants, and hand creams containing anionic emulsifying agents. Daily chlorhexidine bathing is simple to implement and relatively inexpensive and may be an important adjunctive intervention to barrier precautions to reduce acquisition and the subsequent development of infection.

10. Tenth recommendation: If an outbreak is suspected it is recommended to identify the causative organism with molecular typing methods.

Rationale: Studies of outbreaks based on the phenotypic characteristics of microorganisms (antigenic properties, metabolic or antibiotic resistance) are limited and do not provide conclusive differences or similarities between them. Therefore, molecular typing methods, to be able to recognize epidemiologically-linked isolates derived from a common precursor microorganism, should be performed. This will also provide understanding of the mechanism of transmission and dissemination and allow strategies to control and eradicate the epidemic to be designed $[47,48]$.

The "Zero Resistance" program encourages hospitals without resources for molecular testing to send MDR isolates to a Reference Laboratory (National Center for Microbiology, Institute of Health Carlos III; [49]), where the microbiological test will be performed free of charge.

\section{Implementation of the "Zero Resistance" program}

Active implementation of this type of program is clearly necessary in order to achieve the desired results [50]. The Agency for Quality Assurance of the Spanish Ministry of Health will promote implementation in collaboration with the 17 Regional Healthcare Authorities through dissemination, coordination and follow-up. Every autonomous region will create a coordinating team led by an intensivist, responsible for contacting hospital management. The hospital management will notify their local infection and patient quality assurance committees and nominate a local coordinating team consisting of at least an intensivist and an intensive care nurse. The necessary resources for the implementation of the project will be provided.
The "Zero Resistance" program includes a web-based teaching module [51]. It is recommended that the local teams keep track of the number of healthcare workers, physicians, nurses and nurse aides that complete the web-based training modules and report their local educational indices to the regional coordinator. These data are available on the training web page.

\section{Assessment of the impact of the "Zero Resistance" project}

The impact of "Zero Resistance", as in all quality programs, must be measured using quality indicators that can be broken down into structure, procedure and outcome indicators. Obviously, outcome measures are of greater interest since they reflect all aspects of care and are the ultimate objectives of the intervention. The proposed indicators are explained in detail in the program, but each local team should decide which indicators to monitor depending on the information systems and efforts necessary to obtain these measurements.

ICUs participating in the "Zero Resistance" program are committed to entering data required for calculation of the relevant indices in the web-based "ENVIN-HELICS" registry [52]. "Zero Resistance" data are recorded through a specific adaptation of the "ENVIN-HELICS" web page [53]. Local coordinators record data for individual patients. Summary descriptive statistics are available on-line for every individual unit, which can directly access its data on a daily basis. Local results are displayed together with the corresponding regional and national values.

\section{Conclusion}

Bacterial resistance to antibiotics is growing day by day, particularly in hospitals, with a significant impact on mortality and morbidity. The lack of new antibiotics, especially for Gram-negative MDR pathogens, aggravates this serious problem as noted by numerous agencies and professional societies. Antibiotics are often incorrectly prescribed: Inadequate antibiotics or incorrect dosage for a particular infection, administration of antibiotics for non-bacterial infections, and excessively long treatment courses are all frequent.

"Zero Resistance" is a project developed by the SEMICYUC with the technical support of the Spanish Ministry of Health, with the main objective of reducing the cumulative incidence of patients with ICU-acquired MDR by $20 \%$. This project contains a bundle of 10 recommendations aimed at improving prescription of antibiotics, detection and prevention of cross-colonization of MDR pathogens, and elimination of reservoirs. This initiative includes an integral patient safety program and educational modules to facilitate its implementation. Adherence to the project and its results will be evaluated through a series of indicators. 


\section{Abbreviations}

ATS/IDSA: American Thoracic Society/Infectious Diseases Society of America; EARSS: European Antimicrobial Resistance Surveillance System; ENVIN: Spanish annual April-to-June ICU National Nosocomial Infection Surveillance Study (Estudio Nacional de Vigilancia de Infección Nosocomial); ESBL: extended spectrum beta-lactamase; ICU: Intensive Care Unit; MDR: multi-drug resistant; MRSA: methicillin-resistant Staphylococcus aureus; SEC: Scientific Expert Committee; SEEIUC: Spanish Society of Intensive Care Nursing; SEMICYUC: Spanish Society of Intensive Care Medicine and Coronary Care Units; VAP: ventilator-associated pneumonia; VRE: vancomycin-resistant enterococcus.

\section{Competing interests}

The authors declare that they have no competing interests.

\section{Acknowledgement}

Members of the Committee are José Garnacho Montero, for the Working Group of Infectious Diseases and Sepsis (GTEI) of the Spanish Society of Critical Care (SEMICYUC); Francisco Álvarez Lerma, Technical Director of Project "Zero Resistance" and Project "Zero Ventilator-associated Pneumonia"; Paula Ramírez Galleymore (GTEI); Miguel Sánchez García, for the Scientific Committee of SEMICYUC; Mercedes Palomar Martínez, Technical Director of Project "Zero Bacteremia"; Luis Álvarez Rocha (GTEl); Fernando Barcenilla Gaite (GTEl); Joaquín Álvarez Rodríguez, for the Working Group of Planning, Organization and Management of SEMICYUC; Mercedes Catalán González, for "ENVIN" (Spanish National ICU Infection Surveillance Program); Inmaculada Fernández Moreno for the Spanish Society of Critical Care Nursing (SEEIUC); Jesús Rodríguez Baño, Advisor in Infectious Diseases; José Campos Advisor in Microbiology; Jesús Ma Aranaz Andrés, Advisor in Preventive Medicine; Yolanda Agra Varela and Carolina Rodríguez Gay, for the Quality Assurance Agency of the Spanish Ministry of Health.

\section{Declarations}

Publication of this article was funded by Subdireccion General de Calidad y Cohesion of the Spanish Ministry of Health.

\section{Author details}

${ }^{1}$ Hospital Vírgen del Rocío, Sevilla, Spain. ${ }^{2}$ Hospital del Mar, Barcelona, Spain. ${ }^{3}$ Hospital La Fé, Valencia, Spain. ${ }^{4}$ Hospital Arnau de Vilanova, Lérida, Spain. ${ }^{5}$ Complejo Hospitalario La Coruña, La Coruña, Spain. ${ }^{6}$ Hospital de

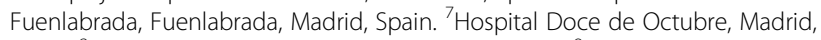
Spain. ${ }^{8}$ Hospital Parc Taulí, Sabadell, Barcelona, Spain. ${ }^{9}$ Hospital Vírgen Macarena, Sevilla, Spain. ${ }^{10}$ Centro Nacional de Microbiología, Majadahonda, Madrid, Spain. ${ }^{11}$ Hospital Ramón y Cajal, Madrid, Spain. ${ }^{12}$ Spanish Ministry of Health, Madrid, Spain. ${ }^{13}$ Hospital Clínico San Carlos, Madrid, Spain.

\section{Published online: 16 March 2015}

\section{References}

1. Boucher HW, Talbot GH, Bradley JS, et al. Bad bugs, no drugs: no ESKAPE! An update from the Infectious Diseases Society of America. Clin Infect Dis. 2009;48:1-12.

2. Antimicrobial resistance interactive database (EARS-Net). Available at: http://www.ecdc.europa.eu/en/healthtopics/antimicrobial_resistance/ database/Pages/database.aspx (Accessed 4 September 2014).

3. Jones RN, Flonta M, Gurler N, Cepparulo M, Mendes RE, Castanheira M. Resistance surveillance program report for selected European nations (2011). Diagn Microbiol Infect Dis. 2014;78:429-36.

4. Cisneros JM, Rodríguez-Baño J, Fernández-Cuenca F, et al. Risk factors for the acquisition of imipenem-resistant Acinetobacter baumannii in Spain: A nationwide study. Clin Microbiol Infect. 2005;11:874-9.

5. Villar M, Cano ME, Gato E, et al. Epidemiologic and clinical impact of Acinetobacter baumannii colonization and infection: A reappraisal. Medicine (Baltimore). 2014;93:202-10.

6. Tacconelli E, Cataldo MA, Dancer SJ, et al. European Society of Clinical Microbiology. ESCMID guidelines for the management of the infection control measures to reduce transmission of multidrug-resistant Gramnegative bacteria in hospitalized patients. Clin Microbiol Infect. 2014;20:1-55.
7. Estudio Nacional De Vigilancia De Infección Nosocomial En Servicios De Medicina Intensiva. Available at: http://hws.vhebron.net/envin-helics/Help/ Informe\%20ENVIN-UCI\%202013.pdf. Accessed Oct 22, 2014.

8. Siegel JD, Rhinehart E, Jackson M, Chiarello L. Healthcare Infection Control Practices Advisory Committee. Management of multidrug-resistant organisms in health care settings, 2006. Am J Infect Control. 2007;35:S165-93.

9. Neidell MJ, Cohen B, Furuya Y, et al. Costs of healthcare- and communityassociated infections with antimicrobial-resistant versus antimicrobialsusceptible organisms. Clin Infect Dis. 2012;55:807-15.

10. García-Garmendia JL, Ortiz-Leyba C, Garnacho-Montero J, Jiménez-Jiménez FJ, Monterrubio-Villar J, Gili-Miner M. Mortality and the increase in length of stay attributable to the acquisition of Acinetobacter in critically ill patients. Crit Care Med. 1999;27:1794-9.

11. Zhuo H, Yang K, Lynch SV, et al. Increased mortality of ventilated patients with endotracheal Pseudomonas aeruginosa without clinical signs of infection. Crit Care Med. 2008;36:2495-503.

12. Palomar M, Álvarez-Lerma F, Riera A, et al. Impact of a national multimodal intervention to prevent catheter-related bloodstream infection in the ICU: the Spanish experience. Crit Care Med. 2013;41:2364-72.

13. Alvarez Lerma F, Sánchez García M, Lorente L, et al. Guidelines for the prevention of ventilator-associated pneumonia and their implementation. The Spanish "Zero-VAP" bundle. Med Intensiva. 2014;38:226-36.

14. Pronovost $P$, Needham D, Berenholtz $S$, et al. An intervention to decrease catheter-related bloodstream infections in the ICU. N Engl J Med. 2006;355:2725-32.

15. Rello J, Lode H, Cornaglia G, Masterton R, Care Bundle Contributors VAP. A European care bundle for prevention of ventilator-associated pneumonia. Intensive Care Med. 2010;36:773-80.

16. Burke JP. Infection control - a problem for patient safety. N Engl J Med. 2003;348:651-6.

17. Pinder M, Bellomo R, Lipman J. Pharmacological principles of antibiotic prescription in the critically ill. Anaesth Intensive Care. 2002;30:134-44.

18. Thomas JK, Forrest A, Bhavnani SM, Hyatt JM, Cheng A, Ballow CH. Pharmacodynamic evaluation of factors associated with the development of bacterial resistance in acutely ill patients during therapy. Antimicrob Agents Chemother. 1998:42:521-57.

19. Garnacho-Montero J, Garcia-Garmendia JL, Barrero-Almodovar A, JimenezJimenez FJ, Perez-Paredes C, Ortiz-Leyba C. Impact of adequate empirical antibiotic therapy on the outcome of patients admitted to the intensive care unit with sepsis. Crit Care Med. 2003;31:2742-51.

20. Heenen S, Jacobs F, Vincent JL. Antibiotic strategies in severe nosocomial sepsis: why do we not deescalate more often? Crit Care Med. 2013:40:1404-9.

21. Garnacho-Montero J, Gutiérrez-Pizarraya A, Escoresca-Ortega A, et al. De-escalation of empirical therapy is associated with lower mortality in patients with severe sepsis and septic shock. Intensive Care Med. 2014;40:32-40.

22. Mokart D, Slehofer G, Lambert J, et al. De-escalation of antimicrobial treatment in neutropenic patients with severe sepsis: results from an observational study. Intensive Care Med. 2014;40:41-9.

23. Pelletier SJ, Crabtree TD, Gleason TG, et al. Waiting for microbiologic data to direct therapy against nosocomial infections in febrile surgical patients: are outcomes worsened? Arch Surg. 1999;134:1300-7.

24. Hranjec T, Rosenberger LH, Swenson B, et al. Aggressive versus conservative initiation of antimicrobial treatment in critically ill surgical patients with suspected intensive-care-unit-acquired infection: a quasi-experimental, before and after observational cohort study. Lancet Infect Dis. 2012;12:774-80.

25. Goeschel CA, Bourgault A, Palleschi M, et al. Nursing lessons from the MHA keystone ICU project: developing and implementing an innovative approach to patient safety. Crit Care Nurs Clin North Am. 2006;18:481-92.

26. Vandijck DM, Labeau SO, Secanell M, Rello J, Blot SI. The role of nurses working in emergency and critical care environments in the prevention of intravascular catheter-related bloodstream infections. Int Emerg Nurs. 2009;17:60-8.

27. Rodríguez-Baño J, Bischofberger C, Álvarez-Lerma F, et al. Vigilancia y control de Staphylococcus aureus resistente a meticilina en hospitales españoles. Documento de consenso GEIH-SEIMC y SEMPSPH. Enferm Infecc Microbiol Clin. 2008;26:285-98.

28. Sunenshine RH, Liedtke LA, Fridkin SK, Strausbaugh LJ. Infectious Diseases Society of America Emerging Infections Network. Management of inpatients 
colonized or infected with antimicrobial-resistant bacteria in hospitals in the United States. Infect Control Hosp Epidemiol. 2005;26:138-43.

29. Martínez Martínez, Eliecer Cano M, Domínguez MA et al. (2007) Cultivos de vigilancia epidemiológica de bacterias resistentes a los antimicrobianos de interés nosocomial En: E. Cercenado y R. Cantón. Procedimientos de Microbiología Clínica. Recomendaciones de la Sociedad Española de Enfermedades Infecciosas y Microbiología Clínica (SEIMC). Available at. http://www.seimc.org/documentos/protocolos/microbiologia.

30. López-Pueyo MJ, Barcenilla-Gaite F, Amaya-Villar R, Garnacho-Montero J. Multirresistencia antibiótica en unidades de críticos. Med Intensiva. 2011;35:41-53

31. Nseir S, Grailles G, Soury-Lavergne A, Minacori F, Alves I, Durocher A. Accuracy of American Thoracic Society/Infectious Diseases Society of America criteria in predicting infection or colonization with multidrugresistant bacteria at intensive-care unit admission. Clin Microbiol Infect. 2010;16:902-8.

32. Nseir S, Di Pompeo C, Diarra M, et al. Relationship between immunosuppression and intensive care unit-acquired multidrug-resistant bacteria: a case-control study. Crit Care Med. 2007;35:1318-23.

33. McKinnell JA, Miller LG, Eells SJ, Cui E, Huang SS. A systematic literature review and meta-analysis of factors associated with methicillin-resistant Staphylococcus aureus colonization at time of hospital or intensive care unit admission. Infect Control Hosp Epidemiol. 2013;34:1077-86.

34. Boyce JM, Pittet D. Guideline for Hand Hygiene in Health-Care Settings: recommendations of the Healthcare Infection Control Practices Advisory Committee and the HICPAC/SHEA/APIC/IDSA Hand Hygiene Task Force. Infect Control Hosp Epidemiol. 2002;23:S3-40.

35. Siegel JD, Rhinehart E, Jackson M, Chiarello L. Guideline for isolation precautions: Preventing transmission of infectious agents in health care settings. Am J Infect Control. 2007;35:565-164.

36. Larson EL, Quiros D, Lin SX. Dissemination of the CDC's Hand Hygiene Guideline and impact on infection rates. Am J Infect Control. 2007;35:666-75.

37. Goodman ER, Platt R, Bass R, Onderdonk AB, Yokoe DS, Huang SS. Impact of an environmental cleaning intervention on the presence of methicillinresistant Staphylococcus aureus and vancomycin-resistant enterococci on surfaces in intensive care unit rooms. Infect Control Hosp Epidemiol. 2008;29:593-9.

38. Carling PC, Parry MF, Bruno-Murtha LA, Dick B. Improving environmental hygiene in 27 intensive care units to decrease multidrug-resistant bacterial transmission. Crit Care Med. 2010;38:1054-9.

39. Matlow AG. Attitudes and beliefs, not just knowledge, influence the effectiveness of environmental cleaning by environmental service workers. Am J Infect Control. 2012;40:260-2.

40. Wendt C, Schinke S, Württemberger M, Oberdorfer K, Bock-Hensley O, von Baum $\mathrm{H}$. Value of whole-body washing with chlorhexidine for the eradication of methicillin-resistant Staphylococcus aureus: a randomized, placebo-controlled, double-blind clinical trial. Infect Control Hosp Epidemiol. 2007;28:1036-43

41. Borer A, Gilad J, Porat N, et al. Impact of $4 \%$ chlorhexidine whole-body washing on multidrug-resistant Acinetobacter baumannii skin colonisation among patients in a medical intensive care unit. J Hosp Infect. 2007:67:149-55.

42. Popovich KJ, Hota B, Hayes R, Weinstein RA, Hayden MK. Effectiveness of routine patient cleansing with chlorhexidine gluconate for infection prevention in the medical intensive care unit. Infect Control Hosp Epidemiol. 2009:30:959-63.

43. Climo MW, Sepkowitz KA, Zuccotti G, et al. The effect of daily bathing with chlorhexidine on the acquisition of methicillin-resistant Staphylococcus aureus, vancomycin-resistant Enterococcus, and healthcare-associated bloodstream infections: results of a quasi-experimental multicenter trial. Crit Care Med. 2009;37:1858-65.

44. Derde LP, Dautzenberg MJ, Bonten MJ. Chlorhexidine body washing to control antimicrobial-resistant bacteria in intensive care units: a systematic review. Intensive Care Med. 2012;38:931-9.

45. Derde LP, Cooper BS, Goossens H, et al. Interventions to reduce colonisation and transmission of antimicrobial-resistant bacteria in intensive care units: an interrupted time series study and cluster randomised trial. Lancet Infect Dis. 2014;14:31-9.

46. Climo MW, Yokoe DS, Warren DK, et al. Effect of daily chlorhexidine bathing on hospital-acquired infection. N Engl J Med. 2013;368:533-42.
47. Singh A, Goering RV, Simjee S, Foley SL, Zervos MJ. Application of molecular techniques to the study of hospital infection. Clin Microbiol Rev. 2006;19:512-30.

48. Sabat AJ, Budimir A, Nashev D, et al. Overview of molecular typing methods for outbreak detection and epidemiological surveillance. Euro Surveill. 2013;18:20380

49. https://cnm-laboratorios.isciii.es/.

50. Hawe CS, Ellis KS, Cairns CJ, Longmate A. Reduction of ventilator-associated pneumonia: active versus passive guideline implementation. Intensive Care Med. 2009;35:1180-6.

51. http://formacion.sanidadmadrid.org/moodle/?lang=en.

52. http://hws.vhebron.net/envin-helics/.

53. http://hws.vhebron.net/resistencia-zero/RZero.asp. 